\title{
Análise das Metodologias e Técnicas de Pesquisas sobre os Ativos Intangíveis nos Eventos da Área Contábil no Brasil
}

\author{
Carlos Magno Costa Silva ${ }^{1}$, Janayna Rodrigues de Morais Luz ${ }^{1}$ \\ José Ribamar Marques de Carvalho ${ }^{2}$, Lúcia Silva Albuquerque ${ }^{1,2}$ \\ Kallyse Priscila Soares de Oliveira ${ }^{1}$ \\ ${ }^{1}$ Universidade Estadual da Paraíba-UEPB \\ ${ }^{2}$ Universidade Federal de Campina Grande-UFCG \\ E-mail de contato: carlosmagnocostaesilva@gmail.com
}

\section{RESUMO}

O presente estudo objetiva mapear a produção científica dos eventos ANPCONT, Congresso USP-CC, ENANPAD e o CBC, acerca da temática dos ativos intangíveis, no decorrer de todas as edições realizadas dos eventos pesquisados, no intuito de delinear as características metodológicas dos artigos e analisar como se encontram distribuídos os trabalhos, conforme os anos, os eventos com relação com o desenvolvimento do tema.A pesquisa classifica-se quanto aos objetivos, em descritiva, com delineamento e coleta de dados bibliográfica, quanto à natureza e a técnica de análise de dados classifica-se como quanti-qualitativa. Os achados encontrados evidenciam um total de 16.607 artigos, sendo contabilizados 133 trabalhos que reportam sobre o tema. O Congresso Brasileiro de Custos foi o que apresentou maior volume de artigos, porém foi o ANPCONT que apresentou maior percentual dos trabalhos sobre o tema quando se compara os números de artigos relacionados por congresso. Os anos mais produtivos da temática foram os de 2004, 2005 e 2007 e coincidem com a divulgação de importantes normas para o tema, tanto a nível nacional, como internacional. O decréscimo das publicações desde 2010 pode refletir a relação do tema com convergência das normas brasileiras com as internacionais de contabilidade. Metodologicamente, foram altos os índices de trabalhos que não expuseram claramente suas metodologias, porém dentre as mais evidentes destaca-se a pesquisa descritiva, bibliográfica, documental indireta e qualitativa.

Palavras-chave: Ativos Intangíveis. Características Metodológicas.ProduçãoCientífica.

\begin{abstract}
This study aims to map the scientific production of events ANPCONT, Congress USP-CC, and BCC ENANPAD, on the theme of intangible assets in the course of all editions held events surveyed in order to outline the methodological characteristics of articles and analyze how the works are distributed, according to the years, the events with respect to the development of the theme. The survey ranks the aims, descriptive, with design and collection of bibliographic data, the nature and technique of data analysis is classified as quantitative and qualitative. The findings show a total of 16,607 articles, with 133 of these works that deal with the subject. The Brazilian Congress of costs showed the greatest volume of articles, but was ANPCONT with the highest percentage of work on the issue when comparing the numbers of items related by Congress. The most productive years were the theme of the 2004, 2005 and 2007 and coincided with the disclosure of important standards for the subject, both national and international level. The decrease of publications since 2010 may reflect the relationship of the subject with convergence of Brazilian standards with international R. Eletr. do Alto Vale do Itajaí - REAVI, v. 5, n. 7, p. I- F,jun., 2016.

ISSN 2316-4190, DOI: 10.5965/2316419005072016037
\end{abstract}


accounting. Methodologically, were high rates of jobs that do not clearly exposed their methodologies, but among the more obvious highlights the descriptive literature, indirect and qualitative research documentary.

Keywords: Intangible Assets. Methodological characteristics.Scientificproduction.

\section{INTRODUÇÃO}

A palavra tangível tem origem que remonta ao grego tango significando tocar. Se opondo ao termo e aplicando-o a contabilidade, temos que "os ativos intangíveis são bens incorpóreos ou imateriais e de suma importância para as organizações na geração de benefícios econômicos, principalmente nos tempos atuais”. (LAGIOIA, 2011, p.72)

Com isso se tem que o valor de uma entidade é o resultado da soma dos ativos tangíveis e intangíveis, sendo que estes últimos apresentam cada vez mais sofisticação nas empresas e nos mercados, além de serem cada vez mais fundamentais para determinar o valor das empresas, valor que pode variar de acordo com o setor de atividade, ciclo de vida do produto e/ou da empresa, dentre outros elementos.

Assim como nas organizações, Niyama e Silva (2010) apontam que a pesquisa sobre ativos em Contabilidade sofreu mudanças nos últimos anos, em que "De trabalhos genéricos, que discutiam o conceito de ativo, seu reconhecimento e mensuração, as novas pesquisas estão mais centradas, abordando temas mais específicos” (Niyama e Silva, 2010, p. 137), citando como exemplos o goodwill, o capital intelectual, dentre outros.

Nesse sentido, o presente estudo procura responder o seguinte problema: Quais as principais características metodológicas das pesquisas apresentadas nos eventos ANPCONT, Congresso USP de Controladoria e Contabilidade, ENANPAD e Congresso Brasileiro de Custos, em todas as suas edições sobre as temáticas dos ativos intangíveis?

O trabalho tem como objetivo geral mapear a produção científica desses eventos acerca da temática dos ativos intangíveis no decorrer de todas as edições realizadas dos eventos pesquisados, tendo como objetivos específicos identificar a evidenciação das características metodológicas dos artigos quanto os objetivos, ao delineamento, a análise e técnica de dados e analisar como se encontram distribuídos os trabalhos, conforme os anos, os eventos, bem como sua relação com o desenvolvimento do tema.

O estudo tem como bases de pesquisa quatro congressos brasileiros da área de contabilidade: Congresso USP de Controladoria e Contabilidade (USP-CC), Congresso 
Brasileiro de Custos (CBC), Encontro da Associação Nacional de pós-graduação e Pesquisa em Administração (ENANPAD) e Associação Nacional de Programas de Pós-Graduação em Ciências Contábeis (ANPCONT), sendo que no ENANPAD deteve-se somente aos trabalhos pertencentes a área contábil. Os eventos foram escolhidos devido à importância que eles apresentam dentro da pesquisa em contabilidade. Por acreditar que o recorte temporal é uma característica delimitada muitas vezes de forma subjetiva, possuindo dessa forma fragilidades, o estudo levou em consideração todas as edições dos eventos selecionados. As categorias metodológicas analisadas seguem o modelo expresso no trabalho de Pontes et al. (2007).

\section{REFENCIAL TEÓRICO}

\subsection{Considerações sobre ativos intangíveis}

Desde os anos de 1970 que os ativos intangíveis são evidenciados e isto se iniciou em países como Estados Unidos e Inglaterra, em que "As informações desses ativos são normalmente reconhecidas em parte, no Balanço patrimonial, e em parte, na Demonstração de resultados" (ZANOTELLIet al., 2013 p. 1). No Brasil, um dos precursores sobre a análise dos ativos intangíveis é Eliseu Martins em 1972 com a sua tese de doutorado "Contribuição à avaliação do ativo intangível”, em que nela traz importantes conceitos que influenciaram todos os aspectos normativos sobre a área neste país.

A nível internacional, instituições como UK AccountancyStandards Board (ASB), o governo americano e o Comitê Internacional de Padrões Contábeis, foram importantes para o tratamento contábil dos ativos intangíveis, em que o ASB através das FRS (Financial Reporting Standard) 10 e 11, publicadas em 1998, influenciaram a IAS 38, publicada pelo Comitê Internacional no ano seguinte e que se tornou obrigatória para as empresas listadas na Bolsa de Valores de Nova York, incluindo as brasileiras, no ano de 2001(MORAES e SZUSTER, 2012). Graças a essas medidas, tornou-se possível o reconhecimento dos intangíveis.

Mesmo tendo passado por um processo de revisão em 2004, a IAS 38, junto com os critérios de reconhecimento apresentados por Martins em 1972, influenciou a Deliberação da CVM (Comissão de Valores Mobiliários) n 488/2005, que “iniciou o processo de divulgação em separado desses ativos nas demonstrações contábeis brasileiras, processo que vem se consolidando com a publicação da Lei $n^{\circ} 11.638 / 2007$ e a adoção dos pronunciamentos do 
Comitê dePronunciamentos Contábeis (CPC)" (ZANOTELLI, AMARAL e SOUZA, 2013), em especial o CPC 04, que converge com a IAS 38 em relação ao objetivo e alcance dos intangíveis.

Definido como "um ativo não monetário identificável sem substância física", tanto para o IAS 38 (2001), quanto para o CPC 04 (2011), os ativos intangíveis possuem uso,voltados para a produção ou provisão, não só de bens como também de serviços, seja para propósitos próprios ou para terceiros. A lei das Sociedades por Ações complementa essa definição trazendo o intangível como "direitos que tenham por objeto bens incorpóreos destinados à manutenção da companhia ou exercidos com essa finalidade, inclusive o fundo de comércio adquirido" (Lei 6404/76, art.179, inciso VI).

Para que uma entidade considere um ativo como intangível, é preciso que se tenham três condições presentes: a identificação, o controle e a geração de benefícios econômicos(LEMES;CARVALHO, 2010). Na primeira condição, “os gastos sobre aquele item devem ser separadamente identificáveis de forma a serem distintos de outros ativos intangíveis." (LEMES; CARVALHO, 2010). Com isso, ele pode ser identificado de duas formas: a primeira é quando "O ativo precisa ser separável, ou seja, ele pode ser vendido, transferido, licenciado, alugado ou trocado" (LAGIOIA, 2011, p. 76) e a segunda é quando "resultar de direitos contratuais ou outros direitos legais, independentemente de tais direitos serem transferíveis ou separáveis da entidade ou de outros direitos e obrigações" (CPC 04, 2011).

O segundo requisito que classifica um ativo como intangível é em relação ao controle que existe, caso a entidade tenha o poder de obter os futuros benefícios, e ao mesmo tempo, restringi-los para terceiros (LEMES; CARVALHO, 2010). Esse controle nem sempre ocorre por meio de um documento legal, já que a entidade pode obter benefícios econômicos futuros de outra forma (CPC 04, 2011), ou seja, consiste num controle de caráter formal. Em relação a esta questão, Lagioia(2011) ainda acrescenta outra forma, denominada de controle não formal, em que ocorre quando os benefícios econômicos futuros são controlados sem que haja a presença de direitos legais. Em relação à geração de benefícios econômicos futuros, são considerados pelo CPC 04, não só a receita de vendas de produtos e serviços, como também a redução de custos ou outros resultados referentes ao uso do ativo pela entidade.

Satisfazendo as condições de ativo intangível, esse item deve ser reconhecido, caso atenda a duas condições: se for provável a geração de benefícios econômicos futuros para a entidade e se seus custos forem mensurados de forma confiável (LAGIOIA, 2011; LEMES e 
CARVALHO, 2010). O reconhecimento ocorre em cinco situações, de acordo com a sua origem conforme a figura a seguir:

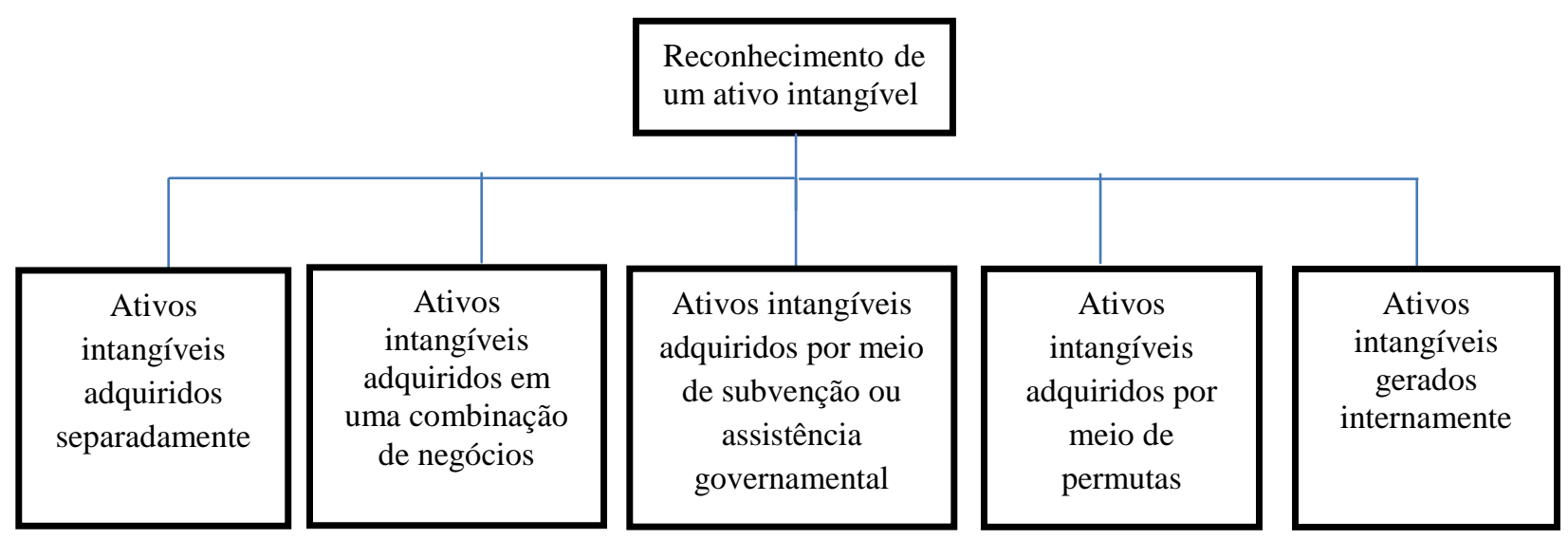

Figura 1: Situações de reconhecimento de um ativo intangível.

Fonte: Lagioia (2011, p. 85).

Cada um dos ativos intangíveis esquematizados acima possui um meio de mensuração. Quando se trata de um intangível adquirido separadamente, ele é mensurado levando em conta o seu preço de compra, com todos os impostos e abatimentos, e todos os custos atribuídos para a sua preparação (LEMES; CARVALHO, 2010). Já quando se trata dos adquiridos por combinação de negócios, ele deve ser reconhecido a valor justo, caso atenda aos critérios de reconhecimento de um ativo, pois do contrário deverá ser evidenciado na adquiridacomo um ágio. (LAGIOIA,2011), conforme o CPC 15- Combinação de Negócios.

Ainda em relação às situações de reconhecimento, há as aquisições por meio de subvenção ou assistência governamentais que apesar de serem regidas pelo CPC 07, trazem no CPC 04 que "uma entidade tem a faculdade de reconhecer inicialmente ao valor justo tanto o ativo intangível quanto a concessão governamental.” e que caso reconheça a valor justo, utilize-se do valor nominal acrescido de gastos diretos com a preparação do ativo.

Nas aquisições por meio de permutas, há duas opções de mensuração: a valor justo, desde que seja feito de forma segura, pois caso contrário ele deve ser "determinado pelo valor contábil do ativo cedido" (LAGIOIA, op. cit. p. 95). Por último, se tem os ativos intangíveis gerados internamente que para serem reconhecidos, a entidade deve separar em duas 
atividades diferentes: a de pesquisa e desenvolvimento, em que o pronunciamento contábil 04 trata os últimos como ativo intangível pelo fato de se terem garantias de geração de benefícios futuros, o que não ocorre na fase da pesquisa.

Assim como um ativo tangível, os intangíveis podem ter vida útil definida, a partir do momento em que se reconhece "a duração ou o volume de produção ou unidades semelhantes que formam essa vida útil" (CPC 04) e com isso ele pode ser amortizado. Caso contrário, devem ser reconhecidos com vida útil indefinida e submetidos ao final do exercício, a verificação de perdas do seu valor recuperável. Todas essas características, junto com toda e quaisquer outras mudanças, sejam positivas ou negativas dentro desses ativos, devem ser evidenciadas, não somente nas demonstrações contábeis como também em outros documentos como os relatórios da administração, as notas explicativas, no parecer de auditoria e em quadros e/ou demonstrações complementares.

\subsection{Considerações sobre a Metodologia Científica}

A ciência consiste numa dentre as várias formas de conhecimento obtidas pelo ser humano, com características bastante próprias. Todas as ciências são caracterizadas por identificarem através de métodos, as percepções humanas de fenômenospor meio de um conjunto de procedimentos, o que torna a ciência "um campo de conhecimentos com técnicas especializadas de verificação, interpretação e inferência da realidade” (Medeiros, 2008 p. 30).

Em se tratando de ciência, a técnica pode ser considerada como a forma de se atingir resultados que possam responder de forma compatível o que se pretende solucionar, podendo ser a parte material, um conjunto de processos, um jeito ou uma habilidade de desenvolver algo, de modo que se possa atender ao objetivo proposto.

É através da técnica de pesquisa científica que executamos qualquer atividade de realização de uma pesquisa. Porém, o método, junto com a técnica, se mostra indispensável para a realização de uma pesquisa. Segundo Lakatos e Marconi (1991, p. 83 apud Reis 2010, p. 54), o método consiste no "conjunto das atividades sistemáticas e racionais que com maior segurança e economia permite alcançar o objetivo e os conhecimentos válidos e verdadeiros, traçando o caminho a ser seguido, detectando erros e auxiliando nas decisões do pesquisador". Desta maneira, o método se constitui em um meio pelo qual através da seleção de processos chega-se a um objetivo de pesquisa, para que se possa estuda-lo e assim, se obter a evolução do conhecimento e o progresso para toda e qualquer ciência. 
Para se atender as necessidades do assunto e da finalidade de uma pesquisa, as pesquisas possuem diversas classificações tipológicas, de acordo o enfoque dado ao trabalho, conforme será visto nas próximas seções a seguir, nas classificações das metodologias científicas que tomou como base as categorias elencadas por Pontes et al (2007) na análise dos estudos brasileiros sobre balancedscorecard.

\subsubsection{Classificação da pesquisa quanto aos objetivos}

Quanto aos objetivos a pesquisa pode ser exploratória, descritiva ou explicativa. A pesquisa exploratória, segundo Andrade (2009, p. 114)é o primeiro passo de todo trabalho científico, pois "busca-se conhecer com profundidade o assunto, de modo a torna-lo mais claro ou construir questões importantes para a condução da pesquisa" (RAUPP; BEUREN, 2003 p. 80).

Segundo Malhotra (2004), a pesquisa exploratória, ajuda na compreensão do problema enfrentado pelo pesquisador, de maneira que identifique aspectos relevantes ou obtenha dados adicionais para o desenvolvimento de uma abordagem. Com isso, pode se ver a importância deste tipo de pesquisa para contribuir com outros trabalhos, bem como com outros tipos de pesquisa, como a descritiva e a exploratória. No caso da Contabilidade, Raupp e Beuren (2003), ainda a acrescentam como requisito para um estudo exploratório, a concentração em algo com necessidade de esclarecimento ou a ser explorado no campo.

$\mathrm{Na}$ pesquisa descritiva se tem a observação, o registro, a análise, a classificação e a interpretação, sem que haja a interferência do pesquisador, portanto, "os fenômenos do mundo físico e humano são estudados, mas não são manipulados pelo pesquisador”. (Andrade, 2009, p. 114). Esse tipo de pesquisa tem como característica a padronização da coleta de dados e busca entender a relação entre as variáveis que são estudadas.

Raupp e Beuren (2003) ainda a consideram um intermediário entre as pesquisas exploratória e explicativa, com grande importância para análise e descrição de problemas de pesquisa na área contábil, procurando assim esclarecer características e/ou aspectos inerentes à área.

Já a pesquisa explicativa "preocupa-se em identificar os fatores que determinam ou contribuem para ocorrência dos fenômenos. Ou seja, este tipo de pesquisa explica o porquê das coisas através dos resultados oferecidos" (GERHARDT; SILVEIRA,2009 p. 36). Nesse sentido é possível perceber que a pesquisa explicativa é a que mais busca aprofundar o conhecimento de uma realidade. Esse tipo de pesquisa é mais complexo, pois, além de 
registrar, analisar e interpretar fenômenos estudados, ela procura identificar seus fatores determinantes.

Para as ciências sociais aplicadas, em especial para a Contabilidade, a pesquisa explicativa é relevante, pois ela por meio de sua maturidade e detalhamento, procura responderà questão-problema (RAUPP; BEUREN, 2003) e com isso tem-se que este tipo de pesquisa não se mostra tão profundo quanto um estudo exploratório, mas também não é tão superficial quanto um descritivo.

\subsubsection{Classificação da pesquisa quanto ao delineamento}

Em relação à classificação da pesquisa quanto ao delineamento, ela se refere aos procedimentos utilizados pelo pesquisador, podendo ser: bibliográfica, documental, experimental, ex post facto, levantamento, estudo de caso, pesquisa-ação e estudo de eventos.

Também denominada de estudo das fontes secundárias, a pesquisa bibliográfica levanta materiais com o objetivo de "colocar o pesquisador em contato direto com tudo aquilo que foi escrito sobre determinado assunto" (MARCONI; LAKATOS, 2011, p. 44). É feita utilizando materiais como livros, dicionários, enciclopédias, periódicos, publicações, artigos científicos, dentre outros e tomada como material referencial para o desenvolvimento de estudo de um tema, mesmo sendo classificada de outra forma. Na relação com os outros tipos de pesquisas, Santos (2005) a considera semelhante ao estudo exploratório e Raupp e Beuren (2003) a tomam como parte das pesquisas experimentais.

A pesquisa documental, ou pesquisa de fontes primárias, recorre a documentos que ainda não foram tomados como base de uma pesquisa, ou seja, que não receberam ainda algum tratamento analítico e/ ou sintético. Este tipo de pesquisa é bastante similar à pesquisa bibliográfica no que diz respeito ao uso das fontes. De acordo com Santos (2005), esse tipo de pesquisa tem como vantagem a confiança nas fontes documentais, o baixo custo e contato do pesquisador com documentos originais.

Já pesquisa experimental "consiste em determinar um objeto de estudo, selecionar as variáveis que seriam capazes de influenciá-lo, definir formas de controle e de observação dos efeitos que a variável produz no objeto" (GIL, 2007 apud GERHARDT E SILVEIRA 2009, p.36.) e pode ser desenvolvida tanto em campo como em laboratório. Possuem como vantagem a clareza, a objetividade e a precisão dos resultados, Santos (2005).

$\mathrm{Na}$ contabilidade, as pesquisas experimentais se referem às pesquisas de campo e decorrem de alguns fatores, principalmente ao fato de elas, geralmente, serem patrocinadas 
pela empresa retratada na pesquisa, de modo que sejam tratadas como estratégicas para que se mostre no meio acadêmico uma boa imagem da empresa retratada no trabalho. Ao contrário da pesquisa experimental, a expost facto não possui controle sob as variáveis e o seu experimento ocorre depois do acontecimento dos fatos.

Os levantamentos são estudos em que os indivíduos são interrogados de forma clara e direta, para se saber o seu comportamento em relação ao tema pesquisado e tem como vantagem o conhecimento, a realidade, a economia, a rapidez e quantificação do conhecimento. Este tipo de pesquisa "é utilizado em estudos exploratórios e descritivos, o levantamento pode ser de dois tipos: levantamento de uma amostra ou levantamento de uma população (...) tendo como coleta de dados os questionários e as entrevistas". (FONSECA 2002, p. 33 apudGERHARDT e SILVEIRA 2009, p. 38).

O tipo de pesquisa estudo de caso é conceituado como o que analisa com profundidade um ou poucos fatos, com o objetivo de obter com maior riqueza de detalhes, conhecimentos sobre o objeto estudado. Esse tipo de pesquisa conforme Santos (2005) “É usada nos estudos exploratórios e no início de pesquisas mais complexas. Tem aplicação em qualquer área do conhecimento." Esse tipo de pesquisa é mais intensivo e faz com que o pesquisador observe in loco, os fenômenos da sua pesquisa, configurando, no caso da contabilidade, a análise e/ou aplicação de instrumentos ou teorias contábeis.

Dentro da categoria dos estudos de caso têm-se também os estudos multicasos que permitem estudar dois ou mais casos sem precisar compara-los. Acerca da pesquisa-ação há pouco a se comentar, pois não se tem muita aplicabilidade na área contábil, já que exige do pesquisador uma estreita relação com as pessoas e objetos da pesquisa, além de uma ação reflexiva sobre si em relação ao meio e ao objeto de estudo.

Por último, há os estudos de evento que consistem "na análise do efeito de informações específicas de determinadas firmas sobre os preços de suas ações." (CAMARGOS; BARBOSA, 2003, p. 1), portanto, se tratam de estudos que visam verificar os efeitos informacionais gerados dentro do mercado financeiro de ações, observando o poder de uma informação, seja positiva ou negativa acerca de uma ação.

\subsubsection{Classificação da pesquisa quanto à natureza e a técnica de análise de dados.}

A cerca da classificação da pesquisa quanto à natureza e técnica de análise de dados da pesquisa define-se que a pesquisa pode ser de três tipos: qualitativa, quantitativa ou quantitativo-qualitativa. A pesquisa qualitativa se caracteriza, segundo Gerhardt e Silveira 
(2009, p. 31), em não se preocupar "com representatividade numérica, mas sim, com o aprofundamento da compreensão de um grupo social, de uma organização", proporcionandouma melhor visão e compreensão do contexto do problema. Ainda sobre esse tipo de pesquisa, Raupp e Beuren (2003) acrescentam que ela descreve a complexidade de um problema, analisando, compreendendo e classificando as variáveis com os processos dinâmicos ocorridos, sendo profunda a forma de tratar o fenômeno estudado.

Diferente da qualitativa, a pesquisa quantitativa emprega um instrumento estatístico como base de análise do processo, seja na coleta, seja no tratamento aos dados. Esses métodos também se opõem pelo fato de que a quantitativa possui uma maior preocupação com comportamento dos acontecimentos. Este tipo de pesquisa, para Malhotra (2004, p. 154) "procura quantificar os dados e, normalmente, aplica alguma forma de análise estatística", e se centra na objetividade, sem que esses dados tenham uma aplicação mecânica.

De acordo com Raupp e Beuren (2003), na pesquisa quantitativa busca-se entender o comportamento que uma população possui. Ainda para os autores, as pesquisas quantitativas na contabilidade brasileira são recentes e apresentam uma grande relevância para a pesquisa. Já a pesquisa quantitativo-qualitativa se utiliza das naturezas das outras duas pesquisas citadas anteriormente, ora predominando um tipo, ora outro, conforme a forma de análise do objeto.

\subsubsection{Classificação da pesquisa quanto à técnica de coleta de dados}

As pesquisas, de acordo com a metodologia são também classificadas quanto à técnica de coleta de dados podendo ser a entrevista, o questionário, a observação e a documentação que pode ser documental ou bibliográfica, dentre outros.

A entrevista, segundo Marconi e Lakatos, (2011p. 111) consiste numa "conversação efetuada face a face, de maneira metódica; proporciona ao entrevistador, verbalmente, a informação necessária" e pode ser: padronizada ou estruturada, despadronizada e não estruturada ou painel. No primeiro tipo, as perguntas são as mesmas para todos os entrevistados, enquanto que no segundo há uma liberdade maior para o entrevistado na elaboração das respostas e o entrevistador pode não seguir um roteiro estabelecido. Já o painel se trata de "um tipo de entrevista que se realiza por meio de uma reunião onde se conversa informalmente, levantando os assuntos desejados, mas de forma coerente, lógica e organizada" (Santos, 2005, p. 234). Vale ressaltar que independente do tipo, a entrevista deve ter um roteiro elaborado previamente. 
Também como método de coleta de dados, o questionário consiste em "uma série ordenada de perguntas, que devem ser respondidas por escrito e sem a presença do pesquisador" (Marconi e Lakatos, 2011, p. 111) e é geralmente devolvido depois de preenchido. Nele deve conter um conjunto de itens ordenados, com perguntas claras e organizadas, podendo ter perguntas abertas ou fechadas, sendo que nas primeiras o entrevistado pode responder de maneira livre as perguntas, enquanto que no questionário fechado as questões possuem várias respostas, em que se deve escolher uma ou mais alternativas.

Em relação à observação, um pesquisador deve examinar determinados aspectos da realidade, levando em conta observar, ouvir e examinar os fatos ou fenômenos que deseja estudar, podendo ser classificado, de acordo com Marconi e Lakatos(2011), em: sistemático, assistemático, participante, não participante, individual, em equipe, na vida real ou em laboratório.

Já as documentações indiretas podem ser de dois tipos. A indireta bibliográfica se trata do recolhimento bibliográfico através de fontes secundárias como, por exemplo, relatórios de pesquisa e estudos históricos, enquanto que a documentação indireta documental consiste na técnica de coleta de dados que utiliza o uso das fontes primárias como contratos, documentos, diários, autobiografias, e no caso da contabilidade as demonstrações contábeis. Esses tipos de documentações apresentam as mesmas características referentes às pesquisas bibliográfica e documental.

\section{PROCEDIMENTOS METODOLÓGICOS}

Assim como os trabalhos que constituem o corpus desta pesquisa, o presente estudo também levará em conta as características descritas nas seções anteriores para a caracterização deste trabalho. Nesse sentido, quanto aos objetivos, à pesquisa é caracterizada como descritiva, pois procura entender a relação entre variáveis. Quanto ao delineamento e a coleta de dados ela é definida como bibliográfica, devido ao contato direto com o assunto a ser realizados por meio de materiais como em livros, artigos, teses, dentre outros. Já quanto à natureza e a técnica de análise de dados, a pesquisa é considerada quanti-qualitativa. Apesar de que os levantamentos são caracterizados como qualitativos pelo fato de descreverem e classificarem variáveis, mas os dados possuem um tratamento estatístico de forma mínima, o 
que faz com que se considere uma pesquisa com as duas características, sendo a qualitativa a característica de maior predomínio.

O estudo utiliza como fontes de pesquisa quatro congressos brasileiros da área de contabilidade: Congresso USP de Controladoria e Contabilidade (USP-CC), Congresso Brasileiro de Custos (CBC), Encontro da Associação Nacional de pós-graduação e Pesquisa em Administração (ENANPAD) e Associação Nacional de Programas de Pós-Graduação em Ciências Contábeis (ANPCONT). A busca das produções se utilizou das palavras-chave: ativo intangível, ativos intangíveis, goodwill, ágio, concessões, marcas, direitos, patentes, doações e subvenções, presentes no título, resumo, palavras-chave e corpo do artigo. Excetuando os dois primeiros, os outros foram escolhidos por serem os mais consolidados na literatura sobre os intangíveis.

Nesses eventos ditos acima, buscou-se analisar os trabalhos contidos no evento com a temática dos ativos intangíveis e os seus tipos mais conhecidos, buscando observar elementos como: quantidade, número e características metodológicas dos artigos com a temática dos ativos intangíveis. O trabalho é inspirado na pesquisa desenvolvida por Pontes et. al. (2007) que realizaram uma análise das metodologias e técnicas de pesquisas adotadas nos estudos brasileiros sobre balancedscorecard. Não se delimitou um recorte temporal para análise, pois o trabalho tem como objetivo observar a produção científica desses eventos acerca da temática dos ativos intangíveis no decorrer das edições efetuadas, além de acreditar que o recorte temporal é uma característica subjetiva, já que muitas vezes a justificativa dos recortes possuem algumas fragilidades. Os eventos aqui citados apresentam os seguintes volumes de edições e os anos de abrangência conforme segue na tabela a seguir:

Tabela 01: Eventos analisados e suas edições e seus períodos

\begin{tabular}{l|l|l}
\hline Evento & $\mathrm{N}^{\mathbf{o}}$ de edições & Período \\
\hline Congresso USP- CC & 13 & 2001 a 2013 \\
\hline CBC & 20 & 1994 a 2013 \\
\hline ENANPAD & 17 & 1997 a 2013 \\
\hline ANPCONT & 7 & 2007 a 2013
\end{tabular}

Fonte: Elaboração própria (2014)

Vale ressaltar que a análise da temática dos ativos intangíveis no evento ENANPAD, delimita-se aos trabalhos pertencentes à área de contabilidade, devido ao evento também abranger as áreas de Administração e Economia, as quais não são o foco da pesquisa e que por isso foram descartadas. A partir destes quatro congressos, a pesquisa encontrou um total de 16.607 artigos como base de dados. Utilizando os termos de pesquisa acima descritos, encontrou-se a quantidade de 270 artigos, dos quais por meio de uma seleção, através da 
leitura dos resumos e da metodologia dos trabalhos, chegou-se a quantia de 133quetratam do tema dos ativos intangíveis. Grande parte dos artigos foi desconsiderada por não abordarem contabilmente o tema estudado.

O método da coleta dos dados ocorreu por meio do acesso dos bancos de dados desses eventos pela hora dos endereços eletrônicos dos eventos disponibilizados por eles. Depois da coleta dos dados, as informações foram processadas em planilhas do Microsoft Excel, possibilitando uma melhor exposição apresentação dos resultados.

\section{APRESENTAÇÃO E DISCUSSÃO DOS RESULTADOS}

Nas próximas seções, expõem-se os volumes de artigos publicados nos eventos Congresso Brasileiro de Custos, Congresso USP, ENANPAD e ANPCONT, bem como volume referente à temática dos ativos intangíveis e os procedimentos metodológicos assumidos sobre o assunto pesquisado.

\subsection{Volume de trabalhos publicados por evento e por edição dos congressos}

Ao se observar a tabela 02 é possível notar que os volumes de publicações nos eventos possuem muitas oscilações, porém é interessante perceber um crescimento constante da produtividade dos eventos entre os anos de 1996 a 2005, tendo como anos de maior publicação os anos de 2008 e de 2010 como os de mais artigos publicados dentre os anos abrangidos pela pesquisa.

Tabela 02: Número de artigos publicados por edição de evento

\begin{tabular}{c|c|c|c|c|c}
$\begin{array}{l}\text { Volume de artigos dos } \\
\text { eventos publicados por } \\
\text { ano }\end{array}$ & CBC & ENANPAD & Congresso USP & ANPCONT & Total \\
\hline 1994 & 27 & - & - & - & 27 \\
\hline 1995 & 97 & - & - & - & 97 \\
\hline 1996 & 45 & - & - & - & 45 \\
\hline 1997 & 51 & 243 & - & - & 294 \\
\hline 1998 & 79 & 250 & - & - & 329 \\
\hline 1999 & 113 & 270 & - & - & 383 \\
\hline 2000 & 166 & 364 & - & - & 530 \\
\hline 2001 & 143 & 426 & 67 & - & 636 \\
\hline 2002 & 200 & 552 & 85 & - & 837 \\
\hline 2003 & 140 & 627 & 101 & - & 868 \\
\hline 2004 & 242 & 791 & 103 & - & 1136 \\
\hline 2005 & 350 & 785 & 100 & - & 1235 \\
\hline 2006 & 212 & 842 & 150 & - & 1204 \\
\hline
\end{tabular}




\begin{tabular}{c|c|c|c|c|c}
2007 & 238 & 886 & 120 & 49 & 1293 \\
\hline 2008 & 265 & 998 & 84 & 48 & 1395 \\
\hline 2009 & 253 & 772 & 68 & 105 & 1198 \\
\hline 2010 & 277 & 854 & 101 & 80 & 1312 \\
\hline 2011 & 199 & 873 & 104 & 101 & 1277 \\
\hline 2012 & 235 & 850 & 106 & 96 & 1287 \\
\hline 2013 & 193 & 858 & 54 & 119 & 1224 \\
\hline Total & 3525 & 11241 & 1243 & 598 & 16.607 \\
\hline
\end{tabular}

Fonte: Elaboração própria (2014)

Na próxima tabela, foram descritosdentro desse volume dos artigos, aqueles que são referentes ao tema dos ativos intangíveis relacionados por congresso.

\subsection{Quantidade de artigos sobre ativo intangível relacionados por congresso}

Após a realização da busca e da seleção dos artigos sobre a temática dos ativos intangíveis, chegou-se a quantidade de 133 artigos dentre o total de 16.607 artigos pertencentes ao universo da pesquisa, representando pouco mais de 0,8\% dos artigos publicados. Com base nesses dados (tabela 3) se observa que como estão distribuídos os trabalhos por evento.

Tabela 03: Números de artigos relacionados por congresso

\begin{tabular}{l|c|c|c}
\hline CONGRESSOS & $\mathbf{N}^{\mathbf{0}}$ DE ARTIGOS & ARTIGOS SOBRE ATIVO INTANGÍVEL & $\begin{array}{c}\text { PERCENTUAL } \\
(\%)\end{array}$ \\
\hline ANPCONT & 598 & 16 & 2,67 \\
\hline USP - CC & 1243 & 29 & 2,33 \\
\hline ENANPAD & 11241 & 23 & 0,20 \\
\hline CBC & 3525 & 65 & 1,84 \\
\hline TOTAL & 16.607 & 133 & 0,80 \\
\hline
\end{tabular}

Fonte: Dados da pesquisa (2014)

Levando em conta os dados apresentados na tabela 02, verifica-se que o Congresso Brasileiro de Custos possui um maior volume de trabalhos publicados pela temática, porém, em aspectos percentuais este não é o evento que possui maior índice de publicações sobre a temática, cabendo este destaque ao ANPCONT com pouco mais de 2,67\% dos seus trabalhos publicados com a temática dos intangíveis, apesar de ser o que possui menor volume de publicação dentre os eventos analisados. O segundo evento com maior número de publicações, tanto em quantidade, quanto em percentual é o Congresso USP de Contabilidade 
e Controladoria com, 29 trabalhos publicados, correspondente a pouco mais de $2,33 \%$ dos trabalhos apresentados até 2013.

\subsection{Números de artigos sobre ativos intangíveis em cada ano estudado}

A tabela 04 a seguir se refere à distribuição do volume de artigos publicados no decorrer dos anos de cada evento. Apesar de todos os eventos não conterem as mesmas quantidades de edições, a tabela foi elaborada tomando o espaço de tempo de publicação do Congresso Brasileiro de Custos, que já possui vinte edições realizadas do evento, a primeira em 1994, podendo assim contemplar todas as edições de todos os eventos, assim como na tabela 02. Entretanto, constatou-se na pesquisa que nos anos de 1994 a 1999, não haviam artigos com a temática, e por isso, essas informações não se encontram explicitadas na tabela a seguir.

Tabela04: Volume de artigos sobre ativos intangíveis em cada ano pesquisado

\begin{tabular}{c|c|c|c|c|c}
\hline Congressos & ANPCONT & Congresso USP CC & CBC & ENANPAD & Total \\
\hline 2000 & - & - & 2 & - & 2 \\
\hline 2001 & - & 1 & 3 & 1 & 5 \\
\hline 2002 & - & 2 & 3 & 1 & 6 \\
\hline 2003 & - & - & 9 & 2 & 11 \\
\hline 2004 & - & 5 & 8 & 1 & 14 \\
\hline 2005 & - & 1 & 9 & 4 & 14 \\
\hline 2006 & - & 6 & 3 & 2 & 11 \\
\hline 2007 & 3 & 3 & 6 & 2 & 14 \\
\hline 2008 & 2 & - & 5 & 2 & 10 \\
\hline 2009 & - & 1 & 4 & 3 & 8 \\
\hline 2010 & 2 & 1 & 7 & 3 & 13 \\
\hline 2011 & 5 & 2 & 1 & 2 & 10 \\
\hline 2012 & 2 & 4 & 3 & - & 9 \\
\hline 2013 & 2 & 3 & 2 & - & 7 \\
\hline Total & 16 & 29 & 65 & 23 & 133 \\
\hline Fonte: Dados da pesquisa & & & &
\end{tabular}

Ao observar o volume de artigos publicados no decorrer dos anos, se verifica uma tendência crescente nos estudos sobre os intangíveis entre os anos de 2000 a 2004, crescimento esse que acompanha o crescimento do volume de publicações, conforme a tabela 2 sendo este último ano, junto com os anos de 2005 e de 2007, os anos com maior volume de publicações sob a temática, com catorze artigos cada ano. É interessante notar que os anos mais produtivos coincidem, com a reformulação da IAS 38, em 2004; com a deliberação da CVM em 2005 e a aprovação da Lei $n^{\circ}$ 11.638/2007 que introduziu o conceito dos intangíveis 
na lei das S/A, todos eles marcos importantes para a consolidação das abordagens desses ativos na contabilidade.

Entretanto, vale o destaque para o decréscimo de publicações que ocorre desde 2010, em que o volume cai até a quantia de sete artigos em 2013, o que pode refletir uma adequação das normas brasileiras em convergência com as normas internacionais, fazendo com que as pesquisas nesta área comecem a tomar um novo rumo. Com isso, percebe-se que antes do processo de normatização os ativos intangíveis eram evidentes nos trabalhos os conflitos existentes no que diz respeito ao triângulo conceitual (reconhecimento, mensuração e evidenciação) deste ativo.

\subsection{Características metodológicas dos artigos}

Nas tabelas a seguir descreve-se como se encontram explicitados nos trabalhos analisados as metodologias desenvolvidas na realização dos estudos dos ativos intangíveis. É importante destacar que houve artigos que apresentaram mais de uma característica metodológica e devido a isso, os totais não correspondem com o número de artigos integrantes da amostra.

Tabela 05: Classificações metodológicas dos artigos quanto aos objetivos.

\begin{tabular}{l|c|c|c|c|c|c}
\hline \multirow{2}{*}{$\begin{array}{c}\text { TIPOS DE } \\
\text { PESQUISA }\end{array}$} & \multicolumn{5}{c|}{ CONGRESSOS } & TOTAL \\
\cline { 2 - 7 } & ANPCONT & USP - CC & ENANPAD & \multicolumn{2}{c}{ CBC } & 38 \\
\hline \multicolumn{2}{|c|}{ Quanto aos Objetivos } & 8 & 12 & 44 \\
\hline Exploratória & 8 & 10 & 8 & 20 & 25 \\
\hline Descritiva & 9 & 9 & 2 & 19 & 42 \\
\hline Explicativa & 0 & 3 & 9 & & 19 \\
\hline Não expresso & 3 & 11 & & & & \\
\hline
\end{tabular}

Fonte: Dados da pesquisa (2014).

A tabela 1, retrata que a ocorrência de não explicitação das metodologias quanto aos objetivos, todavia os trabalhos que explicitaram, percebe-se a preferência dos trabalhos publicados sobre os ativos intangíveis, o predomínio da pesquisa descritiva nos trabalhos. Congresso Brasileiro de Custos apresentou maior quantidade de trabalhos que expressam essas características, tendo os outros eventos dados muito próximos entre si, acerca das pesquisas descritivas. Assim como quanto aos objetivos, a tabela 06 trata sobre o delineamento da pesquisa, constata-se também a alta ocorrência da não explicitação deste aspecto metodológico. 
Tabela 06: Classificação metodológica dos artigos quanto ao delineamento.

\begin{tabular}{|c|c|c|c|c|c|}
\hline \multirow{2}{*}{$\begin{array}{l}\text { TIPOS DE } \\
\text { PESQUISA }\end{array}$} & \multicolumn{4}{|c|}{ CONGRESSOS } & \multirow[b]{2}{*}{ TOTAL } \\
\hline & ANPCONT & USP - CC & ENANPAD & CBC & \\
\hline \multicolumn{6}{|c|}{ Quanto ao Delineamento } \\
\hline Documental & 5 & 7 & 3 & 16 & 31 \\
\hline Bibliográfica & 4 & 9 & 3 & 21 & 37 \\
\hline Levantamento & 0 & 1 & 2 & 5 & 8 \\
\hline Experimental & 0 & 2 & 1 & 3 & 6 \\
\hline Ex post facto & 0 & 0 & 0 & 0 & 0 \\
\hline Estudo de Eventos & 0 & 0 & 1 & 2 & 3 \\
\hline Estudo de Caso & 1 & 6 & 5 & 11 & 23 \\
\hline Pesquisa-ação & 0 & 0 & 0 & 0 & 0 \\
\hline Não expresso & 4 & 7 & 8 & 25 & 44 \\
\hline
\end{tabular}

Fonte: Dados da pesquisa (2014).

Os trabalhos que apresentam os seus delineamentos possuem uma preferência por serbibliográficos e documentais, o primeiro tendo 38 ocorrências e o segundo 31, em que se tem nos trabalhos do CBC e do Congresso USP as maiores evidências desse aspecto metodológico. Na próxima tabela veremos como esses artigos se configuram apresentados quanto à natureza da pesquisa (tabela 06).

Tabela 07: Classificação metodológicas dos artigos quanto à natureza.

\begin{tabular}{|c|c|c|c|c|c|}
\hline \multirow{2}{*}{$\begin{array}{l}\text { TIPOS DE } \\
\text { PESQUISA }\end{array}$} & \multicolumn{4}{|c|}{ CONGRESSOS } & \multirow[b]{2}{*}{ TOTAL } \\
\hline & ANPCONT & USP - CC & ENANPAD & $\mathrm{CBC}$ & \\
\hline \multicolumn{6}{|c|}{ Quanto à Natureza } \\
\hline Qualitativa & 6 & 6 & 3 & 11 & 26 \\
\hline Quantitativa & 5 & 7 & 3 & 8 & 23 \\
\hline $\begin{array}{l}\text { Quantitativa- } \\
\text { Qualitativa }\end{array}$ & 2 & 4 & 5 & 8 & 19 \\
\hline Não expresso & 2 & 11 & 10 & 39 & 62 \\
\hline
\end{tabular}

Fonte: Dados da Pesquisa (2014).

Como se nota, os artigos que mostram a natureza da pesquisa possuem em sua maioria a abordagem qualitativa, com 26 ocorrências, porém tendo a ocorrência das outras abordagens em números bastante próximos, quantitativa 23 e quantitativa-qualitativa 19 ocorrências cada uma, significando que os trabalhos sobre a temática dos ativos intangíveis, possuem uma boa diversificação quanto à natureza da pesquisa. (TABELA 07). Na tabela 08 verificam-secomo os artigos são classificados com relação à técnica de coleta de dados.

Tabela 08: Classificação metodológicas dos artigos quanto à técnica de coleta de dados. 


\begin{tabular}{|c|c|c|c|c|c|}
\hline \multirow{2}{*}{$\begin{array}{r}\text { TIPOS DE } \\
\text { PESQUISA }\end{array}$} & \multicolumn{4}{|c|}{ CONGRESSOS } & \multirow[b]{2}{*}{ TOTAL } \\
\hline & ANPCONT & USP - CC & ENANPAD & CBC & \\
\hline \multicolumn{6}{|c|}{ Técnica de Coleta de Dados } \\
\hline Entrevista & 1 & 2 & 2 & 1 & 6 \\
\hline Questionário & 2 & 3 & 4 & 7 & 16 \\
\hline Observação & 0 & 1 & 1 & 0 & 2 \\
\hline $\begin{array}{l}\text { Documentação } \\
\text { Indireta - } \\
\text { Documental }\end{array}$ & 6 & 9 & 3 & 14 & 32 \\
\hline $\begin{array}{l}\text { Documentação } \\
\text { Indireta - } \\
\text { Bibliográfica } \\
\end{array}$ & 3 & 5 & 3 & 21 & 32 \\
\hline Não expresso & 5 & 11 & 9 & 31 & 56 \\
\hline
\end{tabular}

Fonte: Dados da Pesquisa (2014).

Notando-se as técnicas de coleta de dados apresentadas pelos trabalhos, é notável a preferência pelas pesquisas documental e bibliográfica, com 32 ocorrências cada, o que justifica a utilização das demonstrações contábeis nas pesquisas documentais e o uso do material bibliográfico, como livros, artigos, teses, dissertações, dentre outros materiais, para desenvolver as pesquisas sobre os ativos intangíveis (TABELA 08).

$\mathrm{Na}$ tabela 09 será visto como os trabalhos selecionados se posicionam acerca da sua técnica de coleta de dados.

Tabela 09: Classificação metodológicas dos artigos quanto à técnica de análise de dados.

\begin{tabular}{|c|c|c|c|c|c|}
\hline \multirow{2}{*}{$\begin{array}{l}\text { TIPOS DE } \\
\text { PESQUISA }\end{array}$} & \multicolumn{4}{|c|}{ CONGRESSOS } & \multirow[b]{2}{*}{ TOTAL } \\
\hline & ANPCONT & USP - CC & ENANPAD & CBC & \\
\hline \multicolumn{6}{|c|}{ Técnica de Análise de Dados } \\
\hline Análise Qualitativas & 9 & 11 & 4 & 19 & 43 \\
\hline Análise Quantitativa & 3 & 5 & 4 & 9 & 21 \\
\hline Análise Quanti-Quali & 3 & 7 & 8 & 8 & 26 \\
\hline Não expresso & 1 & 6 & 7 & 22 & 36 \\
\hline
\end{tabular}

Fonte: Dados da Pesquisa (2014)

A partir dos dados acima descritos (Tabela 09), é notória a preferência por desenvolver uma análise qualitativa, o que se infere ao menos que os trabalhos apresentam uma preocupação ao embasar seus estudos de forma teórica e científica. Porém, ao observar essas informações junto com as tabelas anteriores é possível perceber a ocorrência em muitos dos artigos de não apresentam de forma expressa a metodologia abordada, valendo destacar as maiores ocorrências nos trabalhos do Congresso Brasileiro de Custos, inferindo-se que por abranger um maior número de edições num maior número de anos, muitos artigos, 
provavelmente das primeiras edições do evento, não possuíam uma preocupação sobre o método a ser desenvolvido nos trabalhos. Nesse sentido, se percebe que a melhora da construção dos procedimentos metodológicos foi ocorrendo ao longo do tempo, em que se tem que atualmente, a metodologia dos trabalhos deve estar bem definida, pois esta é uma característica que deve ser evidente por ser de extrema importância para a aprovação do trabalho.

Esta inferência pode ser reforçada também ao se perceber que este fenômeno ocorre em menor número nos outros eventos, demonstrando assim que conforme o aumento dos volumes de trabalhos publicados, os autores foram aperfeiçoando as suas pesquisas, bem como a sua preocupação ao evidenciar os métodos utilizados para chegar aos resultados desejados em seus trabalhos, em especial àqueles com a temática dos ativos intangíveis.

\section{CONSIDERAÇÕES FINAIS}

O presente trabalho teve como objetivos: mapear a produção científica dos eventos ANPCONT, Congresso USP de Controladoria e Contabilidade, Congresso Brasileiro de Custos e ENANPAD, com o tema dos ativos intangíveis em todas as edições realizadas do evento; observar a como as características metodológicas se encontram evidentes, no que diz respeito a objetivos, delineamento, análise e técnica de dados e analisar como estão distribuídos esses trabalhos, conforme os anos, eventos e sua relação com o tema.

Dentre o volume de 16.607 artigos dos quatro eventos, 133 foram utilizados para a análise. Quantitativamente, o que apresentou maior volume foi o Brasileiro de Custos, porém foi o ANPCONT que apresentou maior percentual dos trabalhos sobre o tema. Os anos mais produtivos da temática foram os anos de 2004, 2005 e 2007 e coincidem com a divulgação de importantes normas para o tema, tanto a nível nacional, como internacional. O decréscimo das publicações desde 2010 pode refletir a relação do tema com convergência das normas brasileiras com as internacionais de contabilidade.

Metodologicamente, foram altos os índices de trabalhos que não foram identificadas claramente as suas metodologias, o que dificultou a determinação dos métodos em muitos trabalhos, já que não era objetivo do trabalho caracterizar os artigos metodologicamente, porém dentre as mais evidentes destaca-se a pesquisa descritiva, bibliográfica, documental indireta e qualitativa. Entretanto, vale enfatizar que a medida que aumentou os volumes de trabalhos publicados, os autores aperfeiçoaram as suas pesquisas, evidenciando os métodos 
utilizados para chegar aos resultados desejados em seus trabalhos sob a temática dos ativos intangíveis.

O presente trabalho busca contribuir para a investigação da área, bem como serve de subsídios para a aplicação dessa pesquisa como modelo para investigação de outras áreas temáticas, podendo ajudar a exposição de outros assuntos, dentro de outras abordagens mais específicas dentro da área da Contabilidade.Sugere-se para futuras pesquisas analisarem a relação do número de autores por artigo, a distribuição de autores com maior número de publicações, relação das publicações sobre ativo intangível por instituições, como também um estudo sociométrico desses trabalhos.

\section{REFERÊNCIAS}

ANDRADE, Maria Margarida de. Introdução à metodologia do trabalho científico: elaboração de trabalhos na graduação. 9.ed. São Paulo: Atlas,2009.

BRASIL. Lei $\mathbf{n}^{0}$ 6.404, de 15 de dezembro de 1976. Dispõe sobre as Sociedades por Ações. Disponível em: http://www.planalto.gov.br/ccivil_03/Leis/L6404consol.htm. Acesso em 12 de julho de 2014.

CAMARGOS, Marcos Antônio de; BARBOSA, Francisco Vidal. Estudos de evento: Teoria e operacionalização. Caderno de Pesquisas em Administração, São Paulo, v. 10, $\mathrm{n}^{\mathbf{0}} 3$, julho/setembro 2003.

COMITÊ DE PROCEDIMENTOS CONTÁBEIS. CPC 04: ativos intangíveis,2011. Disponível em: <http://www.cpc.org.br>, acesso no dia 20 de outubro de 2013.

GERHARDT, Tatiana Engel; SILVEIRA, Denise Tolfo (organizadoras). Métodos de Pesquisa. $1^{\text {a }}$ Ed. Porto Alegre: Editora da UFRGS, 2009.

LAGIOIA, Umbelina Cravo Teixeira. Pronunciamentos Contábeis na prática. $1^{\mathrm{a}}$ edição. São Paulo. Editora Atlas, 2011.

LEMES, Sirley; CARVALHO, Luis Nelson Guedes de. Contabilidade internacional para graduação: textos, estudos de casos e questões de múltipla escolha. 1. Ed. São Paulo: Atlas, 2010 .

MALHOTRA, Naresh K. Pesquisa de marketing: uma orientação aplicada. $4^{\text {a }}$ Ed. Porto Alegre: Bookman, 2004.

MARCONI, Marina de Andrade; LAKATOS, Eva Maria.Metodologia do trabalho científico: procedimentos básicos, pesquisa bibliográfica, projeto e relatório, publicações e trabalhos científicos. 7.ed.6.reimpr.São Paulo: Atlas, 2011. 
MEDEIROS, João Bosco. Redação científica: a prática de fichamentos, resumos, resenhas. 10.ed. São Paulo. Atlas, 2008.

MORAES, Marcus Vinicius Melo;SZUSTER, Natan.Os efeitos da convergência às normas internacionais de contabilidade no reconhecimento do Goodwill adquirido: Umestudo de caso sobre a aquisição da Texaco pela ULTRAPAR Participações S/A. In: Anais do $12^{\circ}$ Congresso USP de Controladoria e Contabilidade, 2012.

NIYAMA, Jorge Katsumi; SILVA, César Augusto Tibúrcio. Teoria da Contabilidade. 1.ed. São Paulo: Atlas, 2010.

PONTE, Vera Maria Rodrigues et al. Análise das metodologias e técnicas de pesquisas adotadas nos estudos brasileiros sobre balancedscorecard: um estudo dos artigos publicados no período de 1999 a 2006. In: ANPCONT, 1. Ed. 2007.

RAUPP, Fabiano Maury; BEUREN, Ilse Maria. Metodologia da pesquisa Aplicável às Ciências Sociais inComo elaborar trabalhos monográficos em contabilidade. Teoria e prática. $3^{\text {a }}$ edição. São Paulo: Atlas, 2003.

REIS, Linda G. Da teoria à prática o método educar pela pesquisa (MEP). $3^{\text {a }} \mathrm{Ed}$. Revisada e ampliada. Brasília: Senac-DF, 2010.

SANTOS, Izequias Estevam dos Santos. Manual de métodos e técnicas da pesquisa científica.5.ed. Niteroi, RJ: Impetus, 2005.

SILVA, Antônio Carlos Ribeiro. Metodologia da pesquisa aplicada à contabilidade: orientações de estudos, projetos, artigos, relatórios, monografias, dissertações, teses. 2. ed. São Paulo: Atlas, 2006.

ZANOTELLI, Eduardo José; AMARAL, Hudson Fernandes; e SOUZA Antônio Artur de. Os Ativos Intangíveis e a crise de representação contábil. In: Anais do $13^{\circ}$ Congresso USP de Controladoria e Contabilidade, 2013. 